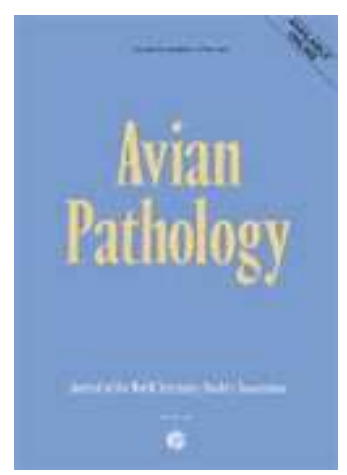

\title{
Deposition of differently sized airborne microspheres in the respiratory tract of chickens
}

\begin{tabular}{|r|l|}
\hline Journal: & Avian Pathology \\
\hline Manuscript ID: & CAVP-2006-0085.R1 \\
\hline Manuscript Type: & Original Research Paper \\
\hline Date Submitted by the \\
Author: & 25-Aug-2006 \\
\hline Komplete List of Authors: & $\begin{array}{l}\text { Corbanie, Evy; Ghent University, Laboratory of Pharmaceutical } \\
\text { Technology } \\
\text { Matthijs, Mieke; Utrecht University, Department of Farm Animal } \\
\text { Health, Faculty of Veterinary Medicine } \\
\text { van Eck, Jo; Utrecht University, Department of Farm Animal Health, } \\
\text { Faculty of Veterinary Medicine } \\
\text { Remon, Jean Paul; Ghent University, Laboratory of Pharmaceutical } \\
\text { Technology } \\
\text { Landman, Wil; GD, Poultry Health } \\
\text { Vervaet, Chris; Ghent University, Laboratory of Pharmaceutical } \\
\text { Technology }\end{array}$ \\
\hline fluorescent microsphere nebulization, particle inhalation, deposition \\
pattern, respiratory vaccination
\end{tabular}

\section{SCHOLARONE Manuscripts}


Cavp-2006-0085

Deposition of differently sized airborne microspheres in the respiratory tract of chickens

\section{E.A. Corbanie ${ }^{1}$, M.G.R. Matthijs ${ }^{2}$, J.H.H. van Eck $^{2}$, J.P. Remon ${ }^{1}$, W.J.M.}

\section{$\operatorname{Landman}^{3} \&$ C. Vervaet ${ }^{1 *}$}

${ }^{1}$ Laboratory of Pharmaceutical Technology, Faculty of Pharmaceutical Sciences, Ghent University, Ghent, Belgium, ${ }^{2}$ Department of Farm Animal Health, Faculty of Veterinary Medicine, Utrecht University, Utrecht, the Netherlands, ${ }^{3}$ Animal Health Service, Poultry Health Centre, Deventer, the Netherlands

Short title: deposition of microspheres in chickens

\footnotetext{
${ }^{*}$ To whom correspondence should be addressed. Tel: + 3292648069 Fax: + 329 2228236 E-mail: Chris.Vervaet@UGent.be
}

Received: 22 June 2006 
Cavp-2006-0085

Deposition of differently sized airborne microspheres in the respiratory tract of chickens

\author{
E.A. Corbanie ${ }^{1}$, M.G.R. Matthijs ${ }^{2}$, J.H.H. van Eck², J.P. Remon', W.J.M. \\ Landman $^{3} \&$ C. Vervaet ${ }^{*}$
}

\title{
Abstract
}

As a part of the development of an efficient dry powder aerosol vaccine for poultry, the objective of this study was to accurately determine the deposition pattern of nebulized microspheres in the airways of unanaesthetized chickens of different ages (1-day, 2-weeks and 4-weeks old). In a first part of the study, the aerosol administration method was characterized: the influence of different nebulizers and nebulizing protocols on the relative humidity in the exposure chamber, the particle size distributions, the microsphere output and single microsphere percentage were determined. In the second part, birds were exposed to nebulized fluorescently labelled polystyrene microspheres ( 1 to $20 \mu \mathrm{m}$ ). Respiratory and gastro-intestinal tract tissue samples were collected and the number of fluorescent microspheres per sample was determined. In 2- and 4-week-old chickens, microspheres of 5 and $10 \mu \mathrm{m}$, respectively, were too large for deposition in the lungs and air sacs as less than $5 \%$ of these microspheres penetrated into the lower airways. The larger size of microspheres reaching the lower airways of 4-week-old birds was explained by increasing airway dimensions with age. For day-old chickens, deposition in the lungs decreased from 17 to $3 \%$ with increasing particle size $(1-20 \mu \mathrm{m})$, but increased in the air sacs from 6 to 20\%. Consequently, the total deposition percentage in the lower airways was independent of microsphere size and even $20 \mu \mathrm{m}$ particles were able to penetrate into 
the lower airways, which was attributed to mouth breathing of the day-old chickens. 


\section{Introduction}

Spray and aerosol vaccination offer a fast and inexpensive method for immunization of poultry. A coarse spray (100 - $800 \mu \mathrm{m}$ droplets $)$ is generally used for the first vaccination (priming) to prevent severe post-vaccination reactions, while an inhalable aerosol (10 - $1000 \mu \mathrm{m}$ droplets) is preserved for follow-up vaccinations (boosters) to induce an effective immune response by targeting the deep airways (Alexander, 1991; Cargill, 1999). Although sufficient protection may be obtained with high-titre vaccines such as Newcastle disease vaccines, there is room for improvement. Firstly, most nebulizers produce broad droplet size distributions and generate large quantities of non-inhalable droplets during aerosol vaccination. To address this, controlled droplet application devices with a narrower droplet spectrum $(80-100 \mu \mathrm{m})$ were developed (Cargill, 1999). Secondly, the efficiency of vaccines administered by spray might be jeopardized by the use of tap water for reconstitution, since this often contains virucidal agents, such as chlorines (Guittet et al., 1999), by large shear forces which are applied to the liquid in order to transform it into droplets (Swift, 1980) and most importantly, due to inactivation of the vaccine virus by evaporation of droplets after generation (Gough \& Allan, 1973; Yadin \& Orthel, 1978; Landman \& van Eck, 2001). In order to prevent these detrimental effects, the administration of named vaccines as a dry powder aerosol could prove beneficial. The successful application of a dry powder aerosol vaccination with a freeze-dried Newcastle disease vaccine has been described previously (Fournier et al., 1976; Gaudry et al., 1976). However, the application never found large-scale industrial application, probably related to difficulties in obtaining defined narrow size particle spectra. 
If powder vaccines are to be applied commercially, a first requirement should be obtaining accurate knowledge about the deposition patterns of particles of various sizes in the respiratory system. Once the optimum particle sizes for targeting specific sections of the respiratory system have been defined, then the vaccine powders with corresponding narrow particle size distribution could be manufactured.

Deposition of particles produced by aerosol, in human airways is well documented (Hatch, 1961; Swift, 1980; Brain et al., 1985); however, extrapolation from human data to birds is not possible due to the particular characteristics of the avian respiratory system such as air sacs and the flow of air through the lungs (Figure 1). Air is drawn through the lungs when the air sacs expand: $50 \%$ of the air flows through the intrapulmonary primary bronchi and the neopulmonic parabronchi (neopulmo) of the lungs straight into the caudal air sacs (abdominal and caudal thoracic airsacs), while $50 \%$ of the air changes direction towards the paleopulmonic parabronchi (paleopulmo). Upon expiration, the air is directed from the caudal air sacs through the neopulmo where the air flows bidirectional, either towards the intrapulmonary primary bronchi or to the paleopulmo. Hence, the paleopulmo receives air during both inspiration and expiration and in both cases air flows caudalto-cranial through the parabronchi (Fedde, 1980; Fedde, 1998; Powell, 2000).

Previously, studies have been performed to estimate the influence of vaccine droplet size in spray and aerosol vaccination on the immune response (Gough \& Allan, 1973; Villegas \& Kleven, 1976). However, at the time no estimates were made on the exact deposition site of the differently sized droplets. Subsequently, other studies with monodisperse radioactively-labelled microspheres (Hayter \& Besch, 1974; Hayter, 1977; Mensah \& Brain, 1982) or iron oxide particles (Stearns et al., 1987) were performed. The work of Hayter \& Besch (1974), where the deposition 
pattern of particles ranging between 0.1 and $7 \mu \mathrm{m}$ was determined in anaesthetized adult chickens, became the main reference for particle and vaccine deposition in the airways of chickens. According to this study, particles larger than $5 \mu \mathrm{m}$ were mainly detected in the upper airways, while smaller particles were preferentially found in the lower airways. However, the actual particle deposition during vaccination in the field might differ, as anaesthesia is known to change the breathing pattern of birds (Yadin, 1980; Powell, 2000; Ludders, 2001). Anaesthesia was not used in the studies performed by Mensah \& Brain (1982) and by Stears et al. (1987), but these authors used 0.45 and $0.18 \mu \mathrm{m}$ particles, respectively, which are not representative for current aerosol particle sizes. In addition, the mentioned deposition studies were performed on adult chickens, whereas most poultry is vaccinated several times, mainly at younger ages during the rearing period. As particle deposition is affected by the dimensions of the respiratory system (Brain et al., 1985), deposition patterns of airborne particles will differ between adult and young birds.

As an alternative to radioactive microspheres, there is a general tendency to utilize fluorescent microspheres (Prinzen \& Glenny, 1994). The fluorescent microsphere method described by Glenny et al. (1993) has already been used to evaluate lung ventilation (Robertson et al., 1997). However, their system is not suitable for the nebulization of microspheres larger than $3 \mu \mathrm{m}$ and it has to be used under anaesthesia.

Therefore, a nebulization system has been developed for the exposure of unanaesthetized chickens of different ages to aerosols of differently sized fluorescent microspheres ranging from 1 to $20 \mu \mathrm{m}$. After in vitro evaluation of the microsphere administration method, in vivo experiments were performed with day-old, 2-week-old and 4-week-old broilers in order to assess the deposition patterns of microspheres. 


\section{Materials and methods}

\section{Evaluation of the microsphere administration method.}

Exposure chamber and nebulization equipment. The exposure chamber with a volume of $40.6 \mathrm{~L}(25 \times 25 \times 65 \mathrm{~cm})$ was constructed of polycarbonate. The bottom and top of the box were not walled; however, the top was covered with a moistureabsorbent cloth (Wypall ${ }^{\circledR}$ L40 cloth; Kimberly-Clark, Zaventem, Belgium), which acted as a vent filter to prevent excessive air pressure during nebulization. Two inlet holes for the nebulization equipment were made in opposite vertical walls at $50 \mathrm{~cm}$ above the bottom of the box (i.e. about 40 and $30 \mathrm{~cm}$ above the head of day-old and 4week-old chickens, respectively), allowing nebulization with a horizontal trajectory (Figure 2). Two nebulizers were evaluated: a WaltherPilot I spray-head with a $0.5 \mathrm{~mm}$ diameter nozzle (Walther Spritz- und Lackiersysteme, Wuppertal, Germany) coupled to an air compressor (Airpress Compressor HL 215/25; Fribel, Wilrijk, Belgium) and a Pari LC nebulizer coupled to a PariBoy compressor (Pari, Starnberg, Germany). The spray-head was previously described for experimental administration of aerosols to chickens (Landman \& van Eck, 2001; Landman et al., 2004) and Pari nebulizers are commonly used jet nebulizers for human aerosol therapy. A counter-current air stream of the same pressure as that of the nebulizer was introduced in the box at the same height as the nebulizer, creating a turbulent zone in the middle of the box when both flows converged. This prevented droplets and microspheres from impacting on the opposite wall of the exposure chamber and enhanced droplet evaporation such that the microspheres were dry at the time of inhalation. 
Continuous versus interval aerosol generation: effect on relative humidity. To control relative humidity $(\mathrm{RH})$ in the exposure chamber and subsequently allow the complete evaporation of the liquid film around the nebulized microspheres in further experiments, the same moisture-absorbent cloth used as lid was applied to line the rest of the box.

The influence of spray duration and spray interval on $\mathrm{RH}$ in the exposure chamber was evaluated with the Walther Pilot I spray-head: $1.5 \mathrm{ml}$ distilled water was either nebulized continuously (during $70 \mathrm{~s}$ ) or intermittently during $10 \mathrm{~s}$ periods using an interval of $110 \mathrm{~s}$ until the total volume was nebulized (during $14 \mathrm{~min}$ ). These experiments were performed with a spray rate of $1.25 \mathrm{ml} / \mathrm{min}$ and a nebulizing air pressure of 0.5 bar. $\mathrm{RH}$ in the box was monitored in function of time with a humidity logger (Testostor 171-2; Testo, Ternat, Belgium).

Spray rate and nebulizing air pressure: effect on droplet size distributions. The droplet size distributions, which also influence the droplet evaporation, were measured by laser diffraction (Mastersizer-S long bed; Malvern Instruments, Malvern, UK) with the nebulizers held at $4 \mathrm{~cm}$ from the laser beam and $2 \mathrm{~cm}$ from the lens. The influence of spray rate and nebulizing air pressure on the droplet size distribution generated by the Walther Pilot I spray-head was evaluated with distilled water. The air pressure of the spray-head was fixed at 0.5 bar to evaluate the influence of spray rate $(0.75-5 \mathrm{ml} / \mathrm{min})$, while the spray rate was set at $1.25 \mathrm{ml} / \mathrm{min}$ for the evaluation of nebulizing air pressure (0.5 - 2 bar). The PariBoy compressor did not allow variations in the spray conditions and the water droplets produced by the Pari nebulizer were measured as such. All droplet size measurements were performed in 
triplicate. During the $\mathrm{RH}$ and droplet size measurements, room temperature and relative humidity were $22.5^{\circ} \mathrm{C}$ and $27 \%$, respectively.

\section{Characterization of the microsphere aerosols: particle sizes, output and} agglomeration.

Fluorescent microspheres. Custom-designed monodisperse polystyrene microspheres were obtained from Duke Scientific Corporation (Palo Alto, CA, USA). These microspheres were supplied as a $2 \%(\mathrm{w} / \mathrm{v})$ suspension and labelled with a highefficiency fluorochrome, in order to obtain sufficient fluorescent intensity in the tissue samples after inhalation. The following microspheres were used: $1 \mu \mathrm{m}$ and $5 \mu \mathrm{m}$ spheres having a green fluorochrome (excitation and emission wavelength of 470 and $508 \mathrm{~nm}$, respectively) and $3 \mu \mathrm{m}, 10 \mu \mathrm{m}$ and $20 \mu \mathrm{m}$ spheres having a red fluorochrome (excitation and emission wavelength of 560 and $596 \mathrm{~nm}$, respectively). $1 \mu \mathrm{m}$ spheres were nebulized in combination with $3 \mu \mathrm{m}$ spheres and $5 \mu \mathrm{m}$ spheres with $10 \mu \mathrm{m}$ spheres, the different fluorochromes allowing simultaneous analysis. The $20 \mu \mathrm{m}$ spheres were nebulized separately. The number of microspheres per $\mathrm{ml}$ was calculated from the microsphere concentration, the material density (density of polystyrene $=$ $1.06 \mathrm{~g} / \mathrm{ml})$ and the microsphere diameter.

Evaporation of the water film surrounding the nebulized microspheres. A model 3321 Aerodynamic Particle Sizer ${ }^{\circledR}$ spectrometer (TSI Incorporated, Shoreview, MN, USA) was used to measure the aerodynamic particle size of microspheres reaching the bottom of the exposure chamber. The chamber, lined with Wypall ${ }^{\circledR}$ L40 cloth, was open at the bottom and placed on top of the spectrometer with the inlet nozzle of the 
spectrometer in the middle of the chamber base. Three experiments were performed with the Walther Pilot I spray-head: firstly, distilled water without microspheres was nebulized, secondly a 1 and $3 \mu \mathrm{m}$ sphere suspension and thirdly a 5 and $10 \mu \mathrm{m}$ sphere suspension $(0.16 \%(\mathrm{w} / \mathrm{v})$ of each microsphere size in $1.5 \mathrm{ml}$ distilled water). The spray-head (spray rate $=1.25 \mathrm{ml} / \mathrm{min}$, nebulizing air pressure $=0.5 \mathrm{bar}$ ) was operated in a continuous mode until two measurements with a $20 \mathrm{~s}$ sampling duration were made. Ambient temperature and relative humidity were $20^{\circ} \mathrm{C}$ and $36 \%$, respectively.

Output of microspheres. The output of microspheres from the nebulizers was determined by nebulizing $1.5 \mathrm{ml}$ of the microsphere-containing suspensions (concentration:0.04\% (w/v) of each microsphere size in distilled water) in a sealed container (volume: $1 \mathrm{~L}$ ) equipped with a vent filter. The microspheres were combined as described above. The Walther Pilot I spray-head (spray rate $=1.25 \mathrm{ml} / \mathrm{min}$, nebulizing air pressure $=0.5$ bar) was activated for $10 \mathrm{~s}$ using an interval of $110 \mathrm{~s}$ until the reservoir was empty. For the output determination of the Pari nebulizer, spray duration was increased to $30 \mathrm{~s}$ with an interval of $90 \mathrm{~s}$ due to its lower spray rate $(0.4 \mathrm{ml} / \mathrm{min})$. After evaporation of the water, Cellosolve ${ }^{\circledR}$ acetate (2-ethoxyethyl acetate; Sigma-Aldrich, Steinheim, Germany) was added to the container to extract the fluorochromes from the microspheres. The fluorescent signal, which correlates with the number of microspheres, was measured and the number of recovered microspheres was expressed as a percentage of the total number of microspheres in $1.5 \mathrm{ml}$ suspension.

Microsphere agglomeration. The degree of agglomeration was determined by counting the number of microspheres (as singles or in agglomerates) deposited on five 
microscope cover glasses $(20 \times 20 \mathrm{~mm})$, placed on the bottom of the exposure chamber. The cover glasses were subsequently superimposed on a Bürker counting chamber, followed by counting the microspheres with a Wilovert ${ }^{\circledR}$ light microscope (Hund, Wetzlar, Germany). The number of single microspheres was expressed as a percentage of the total number of microspheres per microsphere size.

The influence of spray duration and interval on the agglomeration of microspheres was determined by comparing continuous nebulization with intermittent spraying (spray duration of $10 \mathrm{~s}$ using interval of $110 \mathrm{~s}$ ). Therefore, $1.5 \mathrm{ml}$ of a suspension containing $0.04 \%(\mathrm{w} / \mathrm{v}) 3 \mu \mathrm{m}$ spheres and $0.04 \%(\mathrm{w} / \mathrm{v}) 10 \mu \mathrm{m}$ spheres was nebulized with the Walther Pilot I spray-head (spray rate $=1.25 \mathrm{ml} / \mathrm{min}$ and nebulizing air pressure $=0.5$ bar $)$

Furthermore, both nebulizers were evaluated for their influence on microsphere agglomeration. During these experiments the 1 and $3 \mu \mathrm{m}$ spheres were combined, as were the 5 and $10 \mu \mathrm{m}$ spheres, in a suspension containing $0.16 \%(\mathrm{w} / \mathrm{v}$ ) of each microsphere size. The concentration was increased to $0.53 \%(\mathrm{w} / \mathrm{v})$ for the 20 $\mu \mathrm{m}$ spheres. The Walther Pilot I spray-head was used (spray rate $=1.25 \mathrm{ml} / \mathrm{min}$ and air pressure $=0.5 \mathrm{bar}$ ) to nebulize $1.5 \mathrm{ml}$ of each suspension (intermittent nebulization during $10 \mathrm{~s}$ with $110 \mathrm{~s}$ interval). Additionally, the 1 and $3 \mu \mathrm{m}$ spheres were nebulized using two Pari nebulizers simultaneously, which were placed in counter-current position in the nebulization chamber. Each nebulizer reservoir was filled with 1.5 mlsuspension containing $0.08 \%(\mathrm{w} / \mathrm{v}) 1 \mu \mathrm{m}$ spheres and $0.08 \%(\mathrm{w} / \mathrm{v}) 3 \mu \mathrm{m}$ spheres and was nebulized by intermittent spraying during $30 \mathrm{~s}$ with intervals of $90 \mathrm{~s}$.

\section{Experimental design to study in vivo deposition of nebulized microspheres.}

Broiler chickens (Cobb) were obtained from commercial farms at 2 or 4 weeks of age. 
Day-old chickens (Cobb) were obtained from a commercial hatchery and exposed to the microspheres on the day of hatch. Before exposure, the birds were fasted for at least $12 \mathrm{~h}$. The average weight of the day-old $(n=36), 2$-week-old $(n=43)$ and 4week-old $(\mathrm{n}=24)$ chickens was 46g (SD 3g), 394g (SD 124g) and 1238g (SD 8 g), respectively. The nebulized suspensions were prepared by diluting an aliquot of each microsphere suspension in $1.5 \mathrm{ml}$ distilled water. One series of suspensions contained $0.16 \%(\mathrm{w} / \mathrm{v}) 1 \mu \mathrm{m}$ spheres and $0.16 \%(\mathrm{w} / \mathrm{v}) 3 \mu \mathrm{m}$ spheres and a second series contained $0.16 \%(\mathrm{w} / \mathrm{v}) 5 \mu \mathrm{m}$ spheres and $0.16 \%(\mathrm{w} / \mathrm{v}) 10 \mu \mathrm{m}$ spheres. In the case of the $20 \mu \mathrm{m}$ spheres the concentration was increased to $0.53 \%(\mathrm{w} / \mathrm{v})$. The Walther Pilot I spray-head was operated at a nebulizing air pressure of 0.5 bar and a spray rate of $1.25 \mathrm{ml} / \mathrm{min}$ using the intermittent spraying protocol for the exposure of day-old and 2-week-old chickens to all three microsphere aerosols and of 4-week-old birds to the first two aerosols. An additional experiment was performed using two Pari nebulizers to expose 2 -week-old broilers to 1 and $3 \mu \mathrm{m}$ spheres in order to evaluate the influence of microsphere agglomeration on in vivo results. The same number of 1 and $3 \mu \mathrm{m}$ spheres was nebulized as with the single Walther Pilot I spray-head; however, the microspheres were equally divided over both nebulizers $(0.08 \%(\mathrm{w} / \mathrm{v})$ of both sizes per Pari nebulizer). The spray rate of the Pari nebulizers was $0.4 \mathrm{ml} / \mathrm{min}$ and a nebulization protocol of 30s spraying periods with 90s intervals was used.

For each aerosol type and age category, two extra chickens, exposed to an aerosol of water without microspheres, were used as blank controls. In all in vivo experiments, birds were exposed individually. Complete nebulization lasted for 14 min on average with both nebulizers. However, the chickens remained in the chamber for 20 min during which time they could move freely. All exposures were performed 
at an average ambient temperature of $20^{\circ} \mathrm{C}\left( \pm 2^{\circ} \mathrm{C}\right)$. A summary of the experiments performed is shown in Table 1.

Birds were handled and treated according to a protocol approved by the Ethical Committee of the Faculty of Veterinary Medicine (Ghent University) in agreement with the Belgian regulations on protection and welfare of animals.

Collection of tissue samples. Immediately after exposure, chickens were killed by cervical dislocation and subsequently bled. The skin and feathers were removed to prevent contamination of the internal tissues with microspheres deposited on the body of the chickens. Before removing the sternum completely, it was carefully lifted approximately $2 \mathrm{~cm}$ in order to precisely excise the cranial and caudal thoracic air sacs by transecting the ribs. The lungs were separated from the extrapulmonary primary bronchi, which in turn were separated from the trachea at $1 \mathrm{~cm}$ cranial of the syrinx. The trachea was excised together with the larynx. Additionally, the following parts of the gastro-intestinal tract were sampled: oesophagus with crop and lower beak with tongue. Finally, the anterior part of the head (including the upper beak with the nasal conchae and eyes with accessory glands), obtained by transversally cutting the head at the height of the processus orbitalis of the os temporale, was sampled. In summary, the samples collected were: anterior part of the head (further referred to as 'nose and eyes'), larynx with trachea, syrinx (with extrapulmonary primary bronchi), left and right lung, left and right thoracic air sacs, lower beak with tongue, and oesophagus with crop.

Sample processing and fluorescence measurements. The samples were digested at $60^{\circ} \mathrm{C}$ with $5 \mathrm{ml}$ of a $4 \mathrm{~N} \mathrm{KOH}$-solution, containing $2 \%(\mathrm{v} / \mathrm{v})$ Tween ${ }^{\mathrm{TM}} 80$, per gram of 
tissue. The liquefied tissue samples were subsequently filtered on a solid phase extraction vacuum manifold (Alltech Europe, Lokeren, Belgium), adapted with 3 Swinnex ${ }^{\circledR}$ filter holders (Millipore, Brussels, Belgium) and operating at a vacuum pressure of $40 \mathrm{kPa}$. GF51 glass fibre filters (Schleicher \& Schuell, Dassel, Germany) were used to recover the microspheres and after rinsing the recipients and filters with $20 \mathrm{ml}$ distilled water and $20 \mathrm{ml}$ phosphate buffer $(\mathrm{pH} 7.4)$, the filters were placed in glass test tubes and allowed to air-dry. The dried filters were immersed in $6 \mathrm{ml}$ Cellosolve ${ }^{\circledR}$ acetate for $2 \mathrm{~h}$ to extract the fluorochromes from the microspheres. After removal of the filters, the extracts were centrifuged at $2500 \mathrm{~g}$ for $10 \mathrm{~min}$ to precipitate the remaining fibres and microspheres. Finally, the fluorescence of the samples, which correlates with the number of microspheres present, was measured on a Shimadzu RF-5001PC spectrofluorometer (Shimadzu, Antwerp, Belgium). For the green fluorochrome (1 and $5 \mu \mathrm{m}$ spheres), the excitation and emission wavelengths were set on 470 and $508 \mathrm{~nm}$, respectively, whereas for the red fluorochrome $(3,10$ and $20 \mu \mathrm{m}$ spheres) the excitation and emission settings were 560 and $596 \mathrm{~nm}$, respectively.

Data analysis. The fluorescent signals of the different microspheres were used to calculate the number of microspheres per sample. Per tissue, signals were corrected for background fluorescence by subtracting the signals of the corresponding tissue samples harvested from the blank control chickens. In addition, the results were corrected for microsphere loss during sample processing: stock suspensions $(0.16 \%$ $(\mathrm{w} / \mathrm{v})$ of microspheres in the digestion solution) were filtered, retained microspheres were extracted and fluorescence was measured according to the above described method. The recovery percentage was calculated by comparing the number of 
microspheres detected in the extracts with the number of microspheres initially added to the stock suspensions. The number of microspheres per tissue sample was expressed as a percentage of the total number of microspheres detected in all samples of one chicken.

Statistical analyses (SPSS version 12.0; SPSS, Chicago, IL, USA) of the deposition percentages were considered significant at $P<0.05$. To evaluate the effect of microsphere size and the effect of age for microspheres detected in different chickens, a two-way-ANOVA was used. This allowed comparing the 1,5 and $20 \mu \mathrm{m}$ spheres, the 1, 10 and $20 \mu \mathrm{m}$ spheres, the 3,5 and $20 \mu \mathrm{m}$ spheres, and the 3,10 and $20 \mu \mathrm{m}$ spheres. When microsphere sizes measured in one chicken ( $1 \mathrm{vs} .3 \mu \mathrm{m} ; 5 \mathrm{vs}$. $10 \mu \mathrm{m})$ were evaluated for the influence of microsphere size and age, or when the different tissue samples were compared per microsphere size and age, a multivariate repeated measures ANOVA design was used. In this model, the microsphere size or the tissue sample was the within-subject factor, respectively. The age, which divided the population in subgroups, was used as the between-subject factor for these analyses. The repeated measures design was also used for the evaluation of the influence of different nebulizers, with the nebulizer type as between-subject factor and the microsphere size as within-subject factor. In all ANOVA analyses, the normality of the data was evaluated with the Kolmogorov-Smirnov test. The homogeneity of variances was checked with the Levene's test and the data were transformed if necessary. For the repeated measures designs, the Box's test of Equality of Covariance Matrices was used to evaluate the homogeneity of covariance matrices. A Bonferroni correction was used for post hoc investigation of the effects.

\section{Results}




\section{Evaluation of the microsphere administration method.}

Continuous versus interval aerosol generation: effect on relative humidity. Following continuous nebulization of $1.5 \mathrm{ml}$ water with the Walther Pilot I spray-head, RH reached $75 \%$ within a short time. However, using intermittent nebulization with a 110 s interval between $10 \mathrm{~s}$ nebulization periods, the maximal RH only reached $60 \%$ (Figure 3).

Spray rate and nebulizing air pressure: effect on droplet size distributions. The droplet size distributions produced by the Walther Pilot I spray-head in function of the nebulizing air pressure are shown in Figure 4. The aerosol spectra of the spray-head depended on nebulizing air pressure as the mass median diameter $(\mathrm{D}[\mathrm{v} ; 0.5])$ decreased from $21.2 \mu \mathrm{m}$ to $12.5 \mu \mathrm{m}$ with increasing pressure $(0.5$ - 2 bar). Spray rate did not influence the spectra with $\mathrm{D}[\mathrm{v} ; 0.5]$ varying between 20.1 and $21.8 \mu \mathrm{m}$ and no major differences in distribution width. The Pari nebulizer produced an aerosol with a $\mathrm{D}[\mathrm{v} ; 0.5]$ of $5.4 \mu \mathrm{m}$.

\section{Characterization of the microsphere aerosols: particle sizes, output and} agglomeration.

Evaporation of the water film surrounding the nebulized microspheres. Figure 5

shows the number distribution of aerodynamic particle sizes detected on the bottom of the exposure chamber. Sharp peaks were present at size values which corresponded with the polystyrene microsphere sizes. For the 3, 5 and $10 \mu \mathrm{m}$ spheres, there were no considerable signals at sizes larger than the microsphere size, and peak broadness was 
symmetrical within the limits of regular size distributions of monodisperse polystyrene particles. However, around $1 \mu \mathrm{m}$, a small increase of detected particles was seen at the larger side of the peak (1.1 to $2.0 \mu \mathrm{m}$ ), which comprised $28 \%$ of the particles detected. When water without microspheres was nebulized, most of the water droplets evaporated to sizes smaller than $1 \mu \mathrm{m}$.

Output of microspheres. The output from the Walther Pilot I spray-head was nearly complete, as 92,100 and $87 \%$ of 1,3 and $5 \mu \mathrm{m}$ spheres, respectively, were recovered. The output was lower for the larger microspheres, although 75 and 50\% were still nebulized for the 10 and $20 \mu \mathrm{m}$ spheres, respectively. The output of the Pari nebulizer varied between 1 and $9 \%$, and the same relationship between microsphere size and output was seen as with the spray-head, i.e. lower output for larger spheres.

Microsphere agglomeration. Spray duration and interval clearly influenced the single microsphere percentage as this increased from 68 to $78 \%$ for the $3 \mu \mathrm{m}$ spheres and from 58 to $84 \%$ for the $10 \mu \mathrm{m}$ spheres when an interval was introduced in the nebulization protocol.

The intermittent nebulization was subsequently used to evaluate the agglomeration when microspheres were combined similarly to the in vivo experiments. After nebulization with the Walther Pilot I spray-head, the single microsphere percentage for 1 and $3 \mu \mathrm{m}$ spheres was 5 and 30\%, respectively. This percentage increased to 73 and $84 \%$ for the 5 and $10 \mu \mathrm{m}$ spheres, respectively. No agglomerates were detected after nebulization of the $20 \mu \mathrm{m}$ spheres with the sprayhead, i.e. these microspheres were presented in a monodisperse aerosol cloud. Using 
the Pari nebulizer, the single microsphere percentage was 72 and $87 \%$ for the 1 and 3 $\mu \mathrm{m}$ spheres, respectively.

\section{In vivo deposition of nebulized microspheres.}

Chicken behaviour during exposure. Two- and 4-week-old chickens sat quietly in the exposure chamber and showed a normal (nose) breathing pattern. The air turbulence created during nebulization did not disturb the birds. The day-old chickens were much more active and moved around in the chamber. Additionally, they were continuously peeping, and subsequently partly breathing through the mouth. However, this can be considered as regular behaviour, also observed in commercial farms.

Microsphere recovery after sample processing.

The processing of stock suspensions $(0.16 \%(\mathrm{w} / \mathrm{v})$ of the combined microspheres in digestion solution) showed that the recovery of microspheres was independent of microsphere size and reproducible for all microspheres. For the $1 \mu \mathrm{m}$ and $3 \mu \mathrm{m}$ spheres, 78\% (SD 6\%) and 82\% (SD 2\%) was recovered, respectively. The $5 \mu \mathrm{m}$ and $10 \mu \mathrm{m}$ spheres showed a recovery of $73 \%$ (SD 4\%) and 78\% (SD 2\%), respectively, and the recovery percentage for the $20 \mu \mathrm{m}$ spheres was $78 \%$ (SD $4 \%$ ).

Evaluation of deposition of microspheres in broiler chickens using two different nebulizers. The Walther Pilot I spray-head and the Pari nebulizer were compared by analyzing the deposition patterns in 2-week-old broiler chickens after generating aerosols of $1 \mu \mathrm{m}$ (Figure 6A) and $3 \mu \mathrm{m}$ spheres (Figure 6B). Regarding the $1 \mu \mathrm{m}$ spheres, $60 \%$ (SD 17\%) and 43\% (SD 8\%) were deposited in the upper airways (nose 
and eyes, larynx with trachea and syrinx), while 31\% (SD 12\%) and 49\% (SD 6\%) were detected in the lower airways (lungs and air sacs) using the Walther Pilot I spray-head and the Pari nebulizer, respectively. After nebulization of $3 \mu \mathrm{m}$ spheres, $72 \%$ (SD 21\%) and 71\% (SD 10\%) were found in the upper airways whereas 20 (SD $16 \%$ ) and $22 \%$ (SD 12\%) were deposited in the lower airways with the spray-head and the Pari nebulizer, respectively. When the samples were considered separately in the statistical analysis, the $1 \mu \mathrm{m}$ spheres were deposited in a significant lower percentage in the lungs $(P=0.018)$ and the thoracic air sacs $(P=0.000)$ after nebulization with the Walther Pilot I spray-head. The deposition in all other samples was not significantly influenced by the type of nebulizer.

Influence of microsphere size. The influence of microsphere size on the deposition pattern was evaluated by comparing the deposition percentage of the different microspheres by tissue sample and by age (Figure 7: horizontal comparison within each graph).

For day-old chickens (Figure 7A), the deposition percentage in the nose and eyes of $1 \mu \mathrm{m}$ spheres was significantly lower compared to all other microsphere sizes $(P=0.000$ in all comparisons), while for larger microspheres only 5 and $10 \mu \mathrm{m}$ spheres had a significant different deposition percentage $(P=0.000)$. Similar, but opposite differences were seen in the trachea samples of day-old chickens. Deposition in the lower airways was clearly influenced by microsphere size as the deposition in

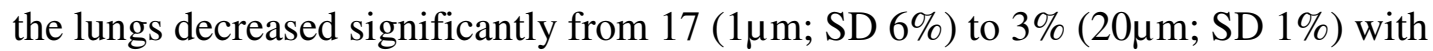
increasing microsphere size ( $P$-values between 0.000 and 0.047$)$. In contrast, the deposition percentage in the thoracic air sacs increased significantly from $6(1 \mu \mathrm{m}$; SD $2 \%)$ to $20 \%(20 \mu \mathrm{m}$; SD $8 \%)$ with increasing microsphere size ( $P$-values between 
0.000 and 0.002 ). The only deviations from these trends in lower airway deposition are that the $20 \mu \mathrm{m}$ sphere deposition percentage in the lungs did not differ significantly from the deposition percentage of the $1 \mu \mathrm{m}$ spheres and that the deposition percentage of $1 \mu \mathrm{m}$ spheres in the air sacs was significantly higher than the $3 \mu \mathrm{m}$ sphere deposition $(P=0.000)$

At 2 weeks of age (Figure 7B), a different deposition pattern was found. The deposition percentage in the nose and eyes samples increased significantly from $35 \%$ (SD $17 \%)$ to $84 \%$ (SD 18\%) when the microsphere size increased from 1 to $10 \mu \mathrm{m}(P$ values between 0.000 and 0.007$)$. Opposite results were found in the remainder of the respiratory tract. The deposition percentage of $20 \mu \mathrm{m}$ spheres in the nose and eyes was $72 \%$ (SD 13\%). This result was not significantly different from the deposition percentage of 5 and $10 \mu \mathrm{m}$ spheres. In the lungs, no significant differences in the deposition of 5, 10 and $20 \mu \mathrm{m}$ spheres were detected, the average deposition percentage ranging between 1.5 and $2.5 \%$. For microspheres smaller than $5 \mu \mathrm{m}$ there was a significant increase in lung deposition with decreasing particle size $(P=0.001)$ : 19 (SD 15\%) and 29\% (SD 12\%) for 3 and $1 \mu \mathrm{m}$, respectively.

The deposition patterns in 4-week-old chickens (Figure 7C) were very similar to those found at 2 weeks. However, at this age significant differences were found between all microsphere sizes for the deposition percentage in the lungs: the amount of $5 \mu \mathrm{m}$ spheres deposited in the lower airways was significantly higher compared to the $10 \mu \mathrm{m}$ spheres: $12 \%$ (SD $8 \%)$ compared to $2 \%$ (SD $2 \%)$, respectively $(P=0.000)$.

Influence of age. The influence of age on the deposition pattern was evaluated by comparing the deposition percentages according to both microsphere size and tissue sample (Figure 7: vertical comparison of graphs). 
Age did not have a significant influence on the deposition of 1 and $3 \mu \mathrm{m}$ spheres in the nose and eyes sample. For the larger spheres $(>3 \mu \mathrm{m})$, a significantly higher deposition was detected in this tissue sample in older chickens in comparison to day-old chickens ( $P$-values between 0.000 and 0.006 ). There was no significant difference between the 2- and 4-week-old chickens regarding deposition in the nose and eyes.

For the deposition in the lower respiratory tract, the largest differences were also noticed between day-old chickens and older chickens, while the percentages in 2and 4-week-old chickens were similar. In day-old chickens, the deposition of 1 and 3 $\mu \mathrm{m}$ spheres in the lungs was significantly lower than in 2-week-old chickens: the deposition percentage decreased for the $1 \mu \mathrm{m}$ spheres from 29 (SD 12\%) to $17 \%$ (SD $6 \%$ ) and for the $3 \mu \mathrm{m}$ spheres from 19 (SD 15\%) to 9\% (SD 4\%) for the 2-week-old and day-old chickens, respectively ( $P=0.043$ for both microsphere sizes). In contrast, the lung deposition of 5 and $10 \mu \mathrm{m}$ spheres was significantly higher in day-old chickens: the deposition percentages in day-old and 2-week-old chickens were 8 (SD $3 \%)$ and $3 \%(\mathrm{SD} 1 \%)$ for the $5 \mu \mathrm{m}$ spheres $(P=0.000)$, respectively, and $4(\mathrm{SD} 1 \%)$ and $1 \%(\mathrm{SD} 1 \%)$ for the $10 \mu \mathrm{m}$ spheres $(P=0.032)$, respectively. No significant influence of age on the lung deposition of $20 \mu \mathrm{m}$ spheres was detected. The deposition percentage in the thoracic air sacs was clearly higher for day-old chickens compared to older chickens ( $P$-values between 0.000 and 0.002$)$, and this difference was more pronounced for larger microspheres (10-fold difference for $20 \mu \mathrm{m}$ spheres). The main difference between the 2- and 4-week-old chickens regarding the deposition in the lower airways was the significantly higher deposition of $5 \mu \mathrm{m}$ spheres in the lungs of the oldest chickens $(P=0.003)$. 
In the gastro-intestinal tract samples, a significant higher deposition percentage of microspheres $<20 \mu \mathrm{m}$ was found in the day-old chickens compared to other birds ( $P$-values between 0.000 and 0.020 for oesophagus and crop samples). The sum of the deposition percentages in the lower beak, oesophagus and crop ranged for the different microsphere sizes between 23 (SD 16\%) and 28\% (SD 16\%) for the dayold chickens, while the percentages ranged between 8 (SD 8\%) and 12\% (SD 6\%) for the 2-week-old chickens and between 10 (SD 12\%) and 13\% (SD 10\%) for the 4week-old birds.

Microsphere distribution throughout the respiratory system. The distribution of the deposition percentages in the different sections of the respiratory system with age and with microsphere size can be derived from Figure 7 by comparing the tissue samples by column.

The nose and eyes samples contained significantly more microspheres of at least $5 \mu \mathrm{m}$ in size at all ages compared to the remaining caudally located tissues $(P=$ 0.000 in all comparisons). The smaller microspheres $(1$ and $3 \mu \mathrm{m})$ were more homogeneously distributed in the respiratory system, as in most comparisons no significant differences were seen between the nose and eyes sample and the lungs. The only significant difference was a higher deposition of $3 \mu \mathrm{m}$ spheres in the nose and eyes of day-old chickens compared to the lungs $(P=0.003)$.

The syrinx only retained low amounts of large fluorescent microspheres,

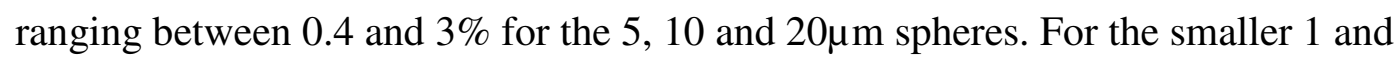
$3 \mu \mathrm{m}$ spheres, deposition in the syrinx was somewhat larger (ranging between 1 and $5 \%$ ); however, these percentages were still significantly lower compared to the deposited amounts in the caudally located lungs ( $P$-values from 0.000 to 0.001$)$. 
When the deposition in the lungs and thoracic air sacs was compared, microspheres smaller than 3 and $5 \mu \mathrm{m}$ were detected in significantly higher amounts in the lungs compared to the air sacs in 2-week-old and 4-week-old chickens $(P=0.000$ in all cases). In day-old chickens, microspheres smaller than $5 \mu \mathrm{m}$ were also detected in higher amounts in the lungs $(P=0.000)$. However, for microspheres larger than $5 \mu \mathrm{m}$ the opposite result was found, since. the deposition in the air sacs was significantly higher compared to the lungs ( $P=0.000$ in all comparisons).

\section{Discussion}

As the microspheres are suspended in water, they are found in droplets after aerosol generation. It is essential for the water to completely evaporate if the spheres are to be inhaled by the chickens in their original size. The evaporation rate is influenced by temperature, relative humidity in the exposure chamber and droplet size itself. A low RH and small droplet size will enhance evaporation rate. Adjusting the spray duration and spray interval allowed control of $\mathrm{RH}$ as a function of time. The use of an interval nebulization protocol reduced the maximal $\mathrm{RH}$ from $75 \%$ after continuous nebulization to $60 \%$, as the moisture had more time to dissipate from the exposure chamber. In this perspective, it was also important to use a low spray rate $(1.25 \mathrm{ml} / \mathrm{min})$ as $\mathrm{RH}$ is expected to reach higher values when introducing larger volumes in the chamber within a certain period of time. Further, the median droplet sizes $(\mathrm{D}[\mathrm{v} ; 0.5])$ produced by the Walther Pilot I spray-head could be decreased by increasing the nebulizing air pressure. This is explained by the droplet forming mechanism, whereby the liquid is first stretched into a thin layer, which then splits into droplets. Both these steps require energy, firstly to overcome viscous forces and 
secondly to overcome an increasing surface tension related to the creation of a larger air-contact surface. When more energy is added, for example by increasing the nebulizing air pressure, it is possible to extend this air-contact surface and to form smaller droplets (Swift, 1980). Although smaller droplets would assure faster evaporation, the lowest air pressure ( 0.5 bar) was selected for further experiments for a number of reasons, the first being the formation of some very large droplets $(>500$ $\mu \mathrm{m})$ at higher air pressures, as can be seen from the higher end-peaks in Figure 4. Although the number of large droplets was low in all cases, their number was clearly increasing with higher nebulizing air pressures. Secondly, a higher air pressure created more turbulence in the exposure chamber, which might stress the chickens, and subsequently alter their breathing pattern. Thirdly, the determination of the particle sizes reaching the bottom of the exposure chamber showed that water droplets generated by the Walther Pilot I spray-head at 0.5 bar evaporated to droplets mainly smaller than $1 \mu \mathrm{m}$. Evaporation of the water film around the microspheres was confirmed after nebulization of microsphere suspensions: the sharp peaks in Figure 5 indicated that no water film remained around microspheres larger than $1 \mu \mathrm{m}$ when they reached the bottom of the exposure chamber. However, the particles in the size range between 1.1 and $2.0 \mu \mathrm{m}$ do not range within regular size limits of monodisperse $1 \mu \mathrm{m}$ polystyrene microspheres and might be due to the presence of some remaining water around the $1 \mu \mathrm{m}$ spheres. As this is only a small part of the total number of $1 \mu \mathrm{m}$ spheres present in the exposure chamber, we do not expect this will influence the deposition pattern detected for the $1 \mu \mathrm{m}$ spheres. The droplet sizes produced by the Pari nebulizer complied with the general requirement of $5 \mu \mathrm{m}$ droplets for reaching the human lungs. The small droplet sizes are yielded due to the presence of impactors (baffles) in the nebulizer reservoir, which will retain larger droplets that subsequently 
will flow back into the reservoir (Atkins et al., 1992). Therefore, it seems unlikely that this nebulizer can be used to deliver microspheres larger than $5 \mu \mathrm{m}$.

As a sufficient number of microspheres had to be available for inhalation by a chicken placed in the exposure chamber, it was essential that only a limited percentage of the microspheres were retained in the nebulizer reservoir. The output of the microspheres was adequate using the Walther Pilot I spray-head; however, it decreased with increasing microsphere sizes. This lower output for larger microspheres was due to the smaller difference between droplet size and microsphere size, reducing the probability that droplets carry microspheres. The extremely low output of the Pari nebulizer, was explained by the fact that the baffles in the reservoir removed large particles from the aerosol, as mentioned previously. The dead volume of the reservoir also contributed to the low output as a considerable fraction of the microsphere suspensions remained in the Pari nebulizer. Overall, the Pari nebulizer seemed less suitable to present a high number of microspheres to the chickens.

Microsphere agglomeration had to be as low as possible in order to prevent the chickens inhaling agglomerates, which are larger than the original microspheres. To minimize this, the probability of microspheres colliding in the air after nebulization should be as low as possible. This could be achieved by varying the nebulization procedure (intermittent nebulization versus continuous nebulization), as confirmed by our results. An additional benefit of using intermittent nebulization during in vivo experiments was that microspheres were available for inhalation over a much longer period. It should be noted that agglomeration was evaluated at the bottom of the box and since agglomerates sediment faster than single microspheres, the percentage of single microspheres presented to the chickens was likely to be larger than in these in vitro experiments. 
Comparison of nebulizers showed that the Walther Pilot I spray-head had a high output but low single microsphere percentage for 1 and $3 \mu \mathrm{m}$ spheres, while the Pari nebulizer had the opposite result. The high output of the Walther Pilot I sprayhead compensates for the low single microsphere percentage, as the absolute number of nebulized single microspheres with the spray-head and the Pari nebulizer was similar for $1 \mu \mathrm{m}$ spheres, whereas for $3 \mu \mathrm{m}$ spheres, the number of nebulized single microspheres was higher after using the spray-head. Comparison of in vivo results obtained with both nebulizers in broilers yielded similar conclusions. Since only 1 and $3 \mu \mathrm{m}$ spheres could be generated with the Pari nebulizer, further experiments were performed with the Walther Pilot I spray-head.

Overall, the deposition pattern of microspheres in the upper and lower airways of unanaesthetized 2- and 4-week-old broilers was similar to the results obtained by Hayter \& Besch (1974). However, accurate comparison between both studies is not possible as Hayter \& Besch did not analyse the different tissue samples separately. Instead, they externally detected the inhaled radioactive aerosol in transverse sections of the body using a Na-I scintillation detector (with possible overlap of different tissues). Even so, they assigned the upper respiratory tract as the main deposition site for particles between 3.7 and $7 \mu \mathrm{m}$ (polydisperse aerosol) in adult, anaesthetized layers. The present study shows that, independent of age, the deposition of microspheres $\geq 5 \mu \mathrm{m}$ is significantly higher in the nose and eyes compared to other tissues. Additionally, there was a significant increase in deposition in the nose and eyes sample in 2- and 4-week-old chickens with increasing microsphere size. The smaller microspheres ( 1 and $3 \mu \mathrm{m})$ are more homogeneously distributed throughout the respiratory system, which confirms the homogeneous distribution of $1.1 \mu \mathrm{m}$ spheres in the study of Hayter \& Besch. These results clearly illustrate the importance 
of sedimentation and impaction as the main deposition mechanisms in the upper respiratory tract, since the contribution of these mechanisms increases proportionally to particle mass. Particle deposition in the nose by the mechanisms mentioned is in agreement with the physiological function of the nose in protecting the vulnerable lower airways from dust and infectious agents. Moreover, sedimentation of large aerosol microspheres on the nose and specifically the eyes will have contributed to their higher deposition percentages in the nose and eyes samples of 2- and 4-week-old chickens when compared to the smaller sized microspheres ( 1 and $3 \mu \mathrm{m})$. This process is important for inducing adequate local and humoral immunity, which will be elicited when vaccine virus reaches the Harderian gland behind the third eyelid in sufficient quantities (Cargill, 1999).

Similar to the nose, the syrinx of the trachea was expected to retain a high number of spheres as airway bifurcations are generally known to capture large inhaled particles due to impaction (Brain et al., 1985). However, in this study, deposition in the syrinx was significantly lower compared to anterior or posterior tissue samples, which suggests that the angle of deflection at the syrinx of chickens is not large enough to induce considerable impaction.

When a low percentage of microspheres are retained in the upper airways, a high percentage of microspheres are able to reach the lower airways. As a consequence, the deposition of $1 \mu \mathrm{m}$ spheres in the lungs of 2- and 4-week-old chickens was higher than the deposition percentage of $3 \mu \mathrm{m}$ spheres. Lower airway deposition of spheres $5 \mu \mathrm{m}$ and larger was reduced to about $5 \%$ of the total deposited number of microspheres for the 2-week-old chickens, independent of microsphere size. In 4-week-old chickens, $5 \mu \mathrm{m}$ spheres were also deposited in the lower airways in considerable amounts, while only microspheres $\geq 10 \mu \mathrm{m}$ showed negligible deposition 
in lungs and air sacs. This agrees with theoretical predictions of particle deposition in upper and lower airways of humans (Hatch, 1961): when particles become larger than $2 \mu \mathrm{m}$, their deposition in the lungs decreases and for $10 \mu \mathrm{m}$ spheres, the probability of escaping deposition in the upper respiratory tract is essentially zero. However, in the present study, this cut-off size for deposition in upper or lower respiratory tract is additionally influenced by age and subsequent increasing airway dimensions. The wider conducting airways allowed larger microspheres to penetrate into the lungs, explaining the increase in cut-off size for deposition in upper and lower respiratory tract from $5 \mu \mathrm{m}$ for 2 -week-old chickens to $10 \mu \mathrm{m}$ for 4 -week-old chickens. When a secondary aerosol vaccination is performed with an Atomist ${ }^{\circledR}$ nebulizer, which is commonly used in the field, 40 to $90 \%$ of the droplets evaporate after nebulization to particles of about 2 to $5 \mu \mathrm{m}$ (Yadin \& Orthel, 1978). This would result in a good vaccine distribution and immune response in 4-week-old chickens; however, in 2week-old chickens, only a part of these vaccine particles $(\leq 3 \mu \mathrm{m})$ will be able to reach the lower airways, thereby inducing a strong immune response, making the technique less efficient in this age category.

Whereas the present results for 2- and 4-week-old chickens are consistent with the findings of Hayter \& Besch (1974), different conclusions can be drawn for the day-old chickens. Although some significant differences were encountered when nose and eyes samples were compared for the influence of microsphere size, the expected increase of deposited microspheres with increasing microsphere size was not seen. Additionally, the total deposition percentages in the lower airways (sum of lungs and air sacs) of day-old chickens did not differ for small and large microspheres. Significant higher percentages of microspheres $\geq 5 \mu \mathrm{m}$ were found in the lower airways of day-old chickens compared to older birds, whereas the conducting airways 
of the day-old birds are much narrower. These findings were attributed to the likely occurrence of mouth breathing during the exposure to the microsphere aerosols. These young chickens were constantly peeping, during which the beaks were opened. Due to the mouth breathing, the nose is partly bypassed and this allows more and larger particles to reach the lower airways as has been shown in humans (Brain et al., 1985) and in chickens (Riddell et al., 1998).

The mouth breathing did not have a significant influence on the deposition of 1 and $\mu \mathrm{m}$ spheres in the nose and eyes as no differences were detected when comparing the three age categories. Thus, for small microspheres, the lower number of microspheres entering the respiratory tract through the nose upon mouth breathing by day-old birds did not result in a lower deposition percentage in the nose. This confirmed the low sensitivity of small microspheres to impaction in the nose. For the larger 5, 10 and $20 \mu \mathrm{m}$ spheres, the mouth breathing of day-old chickens not only reduced the amount of air entering through the nose in comparison to the older nosebreathing chickens, but also the percentage of these microspheres deposited in the nose.

Due to the higher percentage of microspheres reaching the lower airways in day-old chickens, it was possible to evaluate for all microsphere sizes the main deposition site (i.e. lungs or air sacs). In 2- and 4-week-old chickens only the small microspheres reached the lower airways and in all cases, the deposition in the lungs was significantly higher than in the thoracic air sacs. The same was seen for microspheres smaller than $5 \mu \mathrm{m}$ in day-old chickens; however, the opposite was true for microspheres larger than $5 \mu \mathrm{m}$. When microsphere sizes were compared in day-old chickens, an increase of microsphere size reduced the deposition in the lungs, but led to a higher percentage of microsphere deposition in the thoracic air sacs. These 
observations are consistent with the air flow pattern in the respiratory system of chickens (Figure 1). Only small microspheres (1 and $3 \mu \mathrm{m})$ seem to follow the deviating streamline from the intrapulmonary primary bronchi towards the paleopulmonic parabronchi in the lungs, resulting in higher deposition percentages of small microspheres in the paleopulmo. Inertial impaction in the branched neopulmonic parabronchi will contribute to the deposition in the lungs as well. However, the larger microspheres, which have a higher inertia, continue along their original streamline through the intrapulmonary primary bronchi into the caudal air sacs, instead of deviating towards the parabronchi.Consequently, microspheres larger than $5 \mu \mathrm{m}$ that are able to circumvent deposition in the upper airways will preferably be deposited in the air sacs. It should be noted that, although the air seems to flow to the caudal thoracic air sacs in a $90^{\circ}$ angle, this angle is probably much smaller. In the case of a $90^{\circ}$ angle no microspheres larger than $5 \mu \mathrm{m}$ would be detected in the thoracic air sacs due to impaction where the air flow deflects. It is also important to realise that viable vaccine virus particles will replicate and may migrate towards the lower airways even if completely deposited in the upper airways (Hatch, 1961). Therefore, it might be very difficult to completely prevent post-vaccination reactions in primary spray vaccinations, when there is a chance that the particles (or droplets in the current applications) are inhaled. Currently this is solved by spraying close to the day-old chickens in the hatchery, increasing the deposition of droplets onto the birds and decreasing the risk of evaporation and inhalation of smaller particles (Cargill, 1999). It is not likely that microspheres of the sizes used in this study are deposited in the lungs during expiration. When the respiratory muscles reduce the air sac volume, the air flow reverses and this $180^{\circ}$ change in direction of air flow will cause microspheres 
to deposit in the air sacs due to sedimentation when their velocity drops or due to inertial impaction.

Although the gastro-intestinal tract was not our main focus, its cranial part was sampled in order to estimate the amount of swallowed microspheres. Only the anterior part of the gastro-intestinal tract was sampled as it was assumed that the microspheres would not pass through the empty crop during the 20 min exposure period. The mouth breathing of day-old chickens contributed to the significantly higher deposition of microspheres in their gastro-intestinal tract compared to older chickens. Microspheres may also have reached the GI-tract due to clearance from the mucus layer of the nose and the ciliated and non-ciliated regions of trachea and lungs (Mensah \& Brain, 1982). However, these mechanisms are valid for all age categories and therefore, only the larger extent of mouth breathing can explain the significantly higher deposition of microspheres in the GI-tract of day-old chickens.

The $5 \mu \mathrm{m}$ cut-off size for deposition of microspheres in the upper and lower airways, as determined on anaesthetized adult layers by Hayter \& Besch (1974), also applied to the unanaesthetized 2-week-old broilers of our study. For broilers close to the slaughter age, the cut-off size, as derived from the current aerosol experiments, is $10 \mu \mathrm{m}$. Thus, for these two ages our results agree with the previously reported deposition data despite the fact that we did not use anaesthesia and broiler chickens were used instead of layers. In contrast, in day-old chickens, microspheres of even up to $20 \mu \mathrm{m}$ were found to penetrate into the lower airways probably due to mouth breathing and the subsequent partial bypass of the nose filter.

Knowledge on the deposition pattern of differently sized particles in the respiratory system of chickens as presented here is essential if an effective dry powder aerosol vaccine is to be developed. For secondary vaccinations, a powder vaccine 
with a narrow particle size distribution of 3 to $5 \mu \mathrm{m}$, which will target the whole respiratory system, should be aimed for. In contrast, in day-old chickens the likely occurrence of mouth breathing allowed $20 \mu \mathrm{m}$ spheres to reach the lower airways, which should be prevented during a primary vaccination. Therefore, a powder vaccine composed of coarser particles applied over a short distance to chickens as in the current hatchery vaccination, seems necessary in order to prevent post-vaccination reactions in these birds.

No technical difficulties are expected for the nebulization of a dry powder vaccine because equipment suitable for this purpose is readily available in other industries (e.g. painting or pest control). However, a major challenge for successful development of a dry powder vaccine remains the formulation of a monodisperse powder with low hygroscopicity and good stabilizing capacity for a live attenuated vaccine virus. Additionally, it is important that the nebulization technique can offer a sufficient concentration of vaccine to the chickens in order to elicit an efficient immune response.

\section{Acknowledgements}

We wish to thank the Special Research Fund (BOF) from Ghent University, Belgium for their financial contribution. We thank Daniel Tensy and Bram Vanpeteghem for their help during the in vivo exposures and the processing of the samples and Oliver Bischof for his input in the characterisation of the microsphere aerosols. Els Adriaens is gratefully acknowledged for her contribution to the statistical analyses. 


\section{References}

Alexander, D.J. (1991). Newcastle disease and other paramyxovirus infections. In B.W. Calnek (Ed.), Diseases of Poultry, 9th edn (pp. 496-519). Ames: Iowa State University Press.

Atkins, P.J., Barker, N.P. \& Mathisen, D. (1992). The design and development of inhalation drug delivery systems. In A.J. Hickey (Ed.), Pharmaceutical Inhalation Aerosol Technology (pp. 155-185). New York: Marcel Dekker.

Brain, J.D., Valberg, P.A. \& Sneddon, S. (1985). Mechanisms of aerosol deposition and clearance. In F. Morén, M.T. Newhouse \& M.B. Dolovich (Eds.), Aerosols in Medicine. Principles, Diagnosis and Therapy (pp. 123-145). Amsterdam: Elsevier.

Cargill, P.W. (1999). Vaccine administration in poultry. In Practice, 21, 323-328.

Fedde, M.R. (1980). Structure and gas-flow pattern in the avian respiratory system. Poultry Science, 59, 2642-2653.

Fedde, M.R. (1998). Relationship of structure and function of the avian respiratory system to disease susceptibility. Poultry Science, 77, 1130-1138.

Fournier, J.M., Gaudry, D., Moreau, Y., Balençon, M. \& Fontanges, R. (1976). Dry aerosol vaccination against Newcastle disease: I. Safety and activity controls on chickens. Development in Biological Standardisation, 33, 269-272.

Gaudry, D., Balençon, M., Fournier, J.M. \& Fontanges, R. (1976). Dry aerosol vaccination against Newcastle disease: II. Serological response in chicks. Development in Biological Standardisation, 33, 273-278. 
Glenny, R.W., Bernard, S. \& Brinkley, M. (1993). Validation of fluorescent-labelled microspheres for measurement of regional organ perfusion. Journal of Applied Physiology, 74, 2585-2597.

Gough, R.E. \& Allan, W.H. (1973). Aerosol vaccination against Newcastle disease: the influence of vaccine diluent. The Veterinary Record, 93, 458-461.

Guittet, M., Meulemans, G., Vindevogel, H. \& Duchatel, J.P. (1999). Avian vaccines. In P.P. Pastoret, J. Blancou, P. Vannier \& C. Verschueren (Eds.), Veterinary Vaccinology (pp. 395-405). Amsterdam: Elsevier.

Hatch, T.F. (1961). Distribution and deposition of inhaled particles in respiratory tract. Bacteriologic reviews, 25, 237-240.

Hayter, R.B. (1977). Technique for exposure and detection of inhaled aerosols in poultry. Poultry Science, 56, 949-952.

Hayter, R.B. \& Besch, E.L. (1974). Airborne particle deposition in the respiratory tract of chickens. Poultry Science, 53, 1507-1511.

Landman, W.J.M., Corbanie, E.A., Feberwee, A. \& van Eck, J.H.H. (2004). Aerosolization of Mycoplasma synoviae compared with Mycoplasma gallisepticum and Enterococcus faecalis. Avian Pathology, 33, 210-215.

Landman, W.J.M. \& van Eck, J.H.H. (2001). Aerosolization of Newcastle disease vaccine virus and Enterococcus faecalis. Avian Diseases, 45, 684-687.

Ludders, J.W. (2001). Inhaled anesthesia for birds. In R.D. Gleed \& J.W. Ludders (Eds.), Recent advances in veterinary anesthesia and analgesia: companion animals. Ithaca (NY): International Veterinary Information Service (www.ivis.org). 
Mensah, G.A. \& Brain, J.D. (1982). Deposition and clearance of inhaled aerosol in the respiratory tract of chickens. Journal of Applied Physiology, 53, 14231428.

Powell, F.L. (2000). Respiration. In G.C. Whittow (Ed.), Sturkie's Avian Physiology, 5th edn (pp. 233-264). San Diego: Academic Press.

Prinzen, F.W. \& Glenny, R.W. (1994). Developments in nonradioactive microsphere techniques for blood flow measurement. Cardiovascular Research, 28, 14671475 .

Riddell, C., Schwean, K. \& Classen, H.L. (1998). Inflammation of the bronchi in broiler chickens, associated with barn dust and the influence of barn temperature. Avian Diseases, 42, 225-229.

Robertson, H.T., Glenny, R.W., Stanford, D., McInnes, L.M., Luchtel, D.L. \& Covert, D. (1997). High-resolution maps of regional ventilation utilizing inhaled fluorescent microspheres. Journal of Applied Physiology, 82, 943-953.

Stearns, R.C., Barnas, G.M., Walski, M. \& Brain, J.D. (1987). Deposition and phagocytosis of inhaled particles in the gas-exchange region of the duck, Anas platyrhynchos. Respiration Physiology, 67, 23-36.

Swift, D.L. (1980). Aerosols and humidity therapy. Generation and respiratorydeposition of therapeutic aerosols. American Review of Respiratory Disease, 122, 71-77.

Villegas, P. \& Kleven, S.H. (1976). Aerosol vaccination against Newcastle disease. I. Studies on particle size. Avian Diseases, 20, 179-190.

Yadin, H. (1980). Aerosol vaccination against Newcastle disease: virus inhalation and retention during vaccination. Avian Pathology, 9, 163-170. 
Yadin, H. \& Orthel, F.W. (1978). A study of Newcastle disease vaccine virus in sprays and aerosols. Avian Pathology, 7, 357-371. 


\section{Figure legends}

Figure 1. Respiratory system of chickens (Clav. AS = clavicular air sac; Cran. Th. AS $=$ cranial thoracic air sac; Caud. Th. AS = caudal thoracic air sac; $A b d . A S=$ abdominal air sac). During inhalation, the air sacs expand and air is drawn from the outside through the trachea and primary bronchi, partly towards the caudal air sacs and partly towards the paleopulmonic parabronchi (Fedde, 1998; with permission from Poultry Science Association).

Figure 2. Polycarbonate exposure chamber $(25 \times 25 \times 65 \mathrm{~cm})$ with inlet holes for nebulization equipment and air gun at $50 \mathrm{~cm}$ above the bottom of the chamber.

Figure 3. Relative humidity $(R H)$ in the exposure chamber upon nebulization of 1.5 $\mathrm{ml}$ of water with the Walther Pilot I spray-head (spray rate $=1.25 \mathrm{ml} / \mathrm{min}$ and nebulizing air pressure $=0.5$ bar). $R H$ was measured at different points of time after the start of the nebulization and evaluated for different spraying procedures $(n=1)$. The arrows indicate the end of the nebulization period: 70 s for the continuous nebulization and 14 min for the interval nebulization.

Figure 4. Average droplet size distribution $(n=3)$ produced by the Walther Pilot I spray-head for increasing nebulizing air pressures (spray rate $=1.25 \mathrm{ml} / \mathrm{min}$ ). The results are expressed as a volume distribution (i.e. percentage of droplets with a certain volume are plotted in function of their diameter). 
Figure 5. Average aerodynamic particle diameters detected on the bottom of the exposure chamber $(n=2)$ after nebulization of water without microspheres and nebulization of microspheresuspensions. Sharp, symmetrical peaks indicate complete evaporation of the water film around the microspheres.

Figure 6. Evaluation of deposition of microspheres (A: $1 \mu \mathrm{m}$ spheres; $B$ : $3 \mu \mathrm{m}$ spheres) in 2-week-old broiler chickens using the Walther Pilot I spray-head $(n=10)$ and the Pari nebulizers $(n=5)$. The dotted segments represent the deposition in the upper airways (i.e. nose and eyes, larynx with trachea and syrinx ), the plain segments comprise the deposition in the lower airways (i.e. lungs and thoracic air sacs), and the striped segments show the amount of microspheres in part of the gastro-intestinal tract (i.e. lower beak with tongue and oesophagus with crop). Although some differences can be observed, these are not significant, except for the 1 um spheres deposited in the lungs and the thoracic air sacs.

Figure 7. Average deposition percentages in broilers of different ages (A: day-old; B: 2-weeks-old; C: 4-weeks-old) after nebulization of differently sized fluorescent microspheres with a Walther Pilot I spray-head. For each aerosol type (1 and $3 \mu \mathrm{m}$; 5 and $10 \mu \mathrm{m} ; 20 \mu \mathrm{m}) 10$ birds were used. The dotted segments represent the deposition in the upper airways (i.e. nose and eyes, larynx with trachea, syrinx), the plain segments comprise the deposition in the lower airways (i.e. lungs and thoracic air sacs), and the striped segments show the amount of microspheres in the anterior part of the gastro-intestinal tract (i.e. lower beak with tongue, oesophagus with crop). 


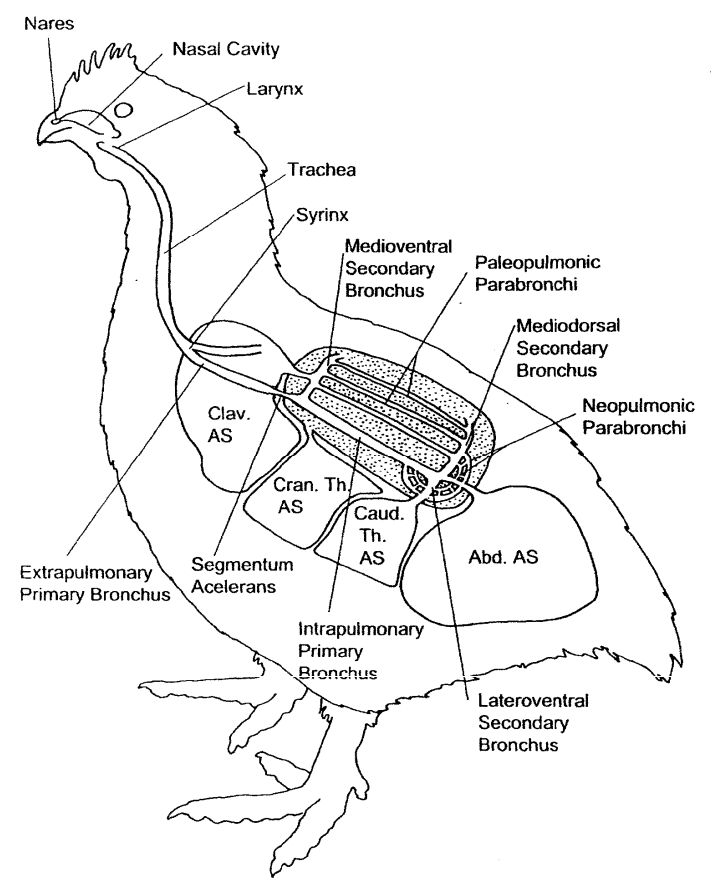

Figure 1. Respiratory system of chickens (Clav. AS = clavicular air sac; Cran. Th. AS = cranial thoracic air sac; Caud. Th. AS = caudal thoracic air sac; Abd. AS = abdominal air sac). During inhalation, the air sacs expand and air is drawn from the outside through the trachea and primary bronchi, partly towards the caudal air sacs and partly towards the paleopulmonic parabronchi (Fedde, 1998; with permission from Poultry Science Association). 


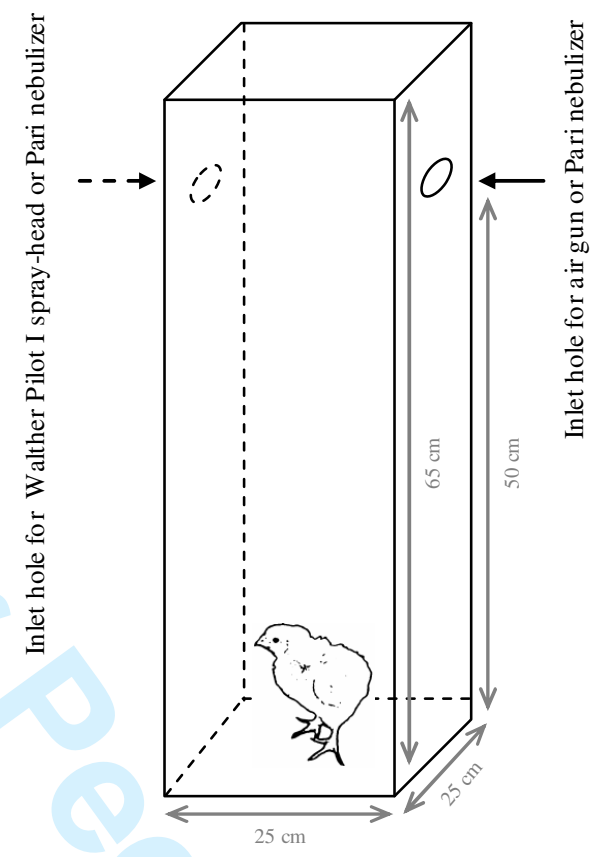

Figure 2. Polycarbonate exposure chamber $(25 \times 25 \times 65 \mathrm{~cm})$ with inlet holes for nebulization equipment and air gun at $50 \mathrm{~cm}$ above the bottom of the chamber. 
Table 1. Overview of performed experiments, with number of exposed chickens and average weight per group of exposed chickens.

\begin{tabular}{lccccc}
\hline Nebulizer & $\begin{array}{c}\text { Age of } \\
\text { chickens }\end{array}$ & Microspheres & $\begin{array}{c}\text { Number of } \\
\text { exposed } \\
\text { chickens }\end{array}$ & $\begin{array}{c}\text { Number of } \\
\text { blank control } \\
\text { chickens }\end{array}$ & $\begin{array}{c}\text { Average weight of } \\
\text { exposed and blank } \\
\text { chickens (g) ( } \pm \text { SD) }\end{array}$ \\
\hline Walther Pilot I & Day-old & $1 \& 3 \mu \mathrm{m}$ & 10 & 2 & $43( \pm 2)$ \\
spray-head & Day-old & $5 \& 10 \mu \mathrm{m}$ & 10 & 2 & $48( \pm 2)$ \\
& Day-old & $20 \mu \mathrm{m}$ & 10 & 2 & $46( \pm 2)$ \\
\cline { 2 - 6 } & 2-weeks-old & $1 \& 3 \mu \mathrm{m}$ & 10 & 2 & $300( \pm 47)$ \\
& 2-weeks-old & $5 \& 10 \mu \mathrm{m}$ & 10 & 2 & $276( \pm 44)$ \\
\cline { 2 - 6 } & 2-weeks-old & $20 \mu \mathrm{m}$ & 10 & 2 & $1295( \pm 98)$ \\
& 4-weeks-old & $1 \& 3 \mu \mathrm{m}$ & 10 & 2 & $1180( \pm 98)$ \\
\hline Pari & 4-weeks-old & $5 \& 10 \mu \mathrm{m}$ & 10 & 2 & $520( \pm 49)$ \\
\hline
\end{tabular}




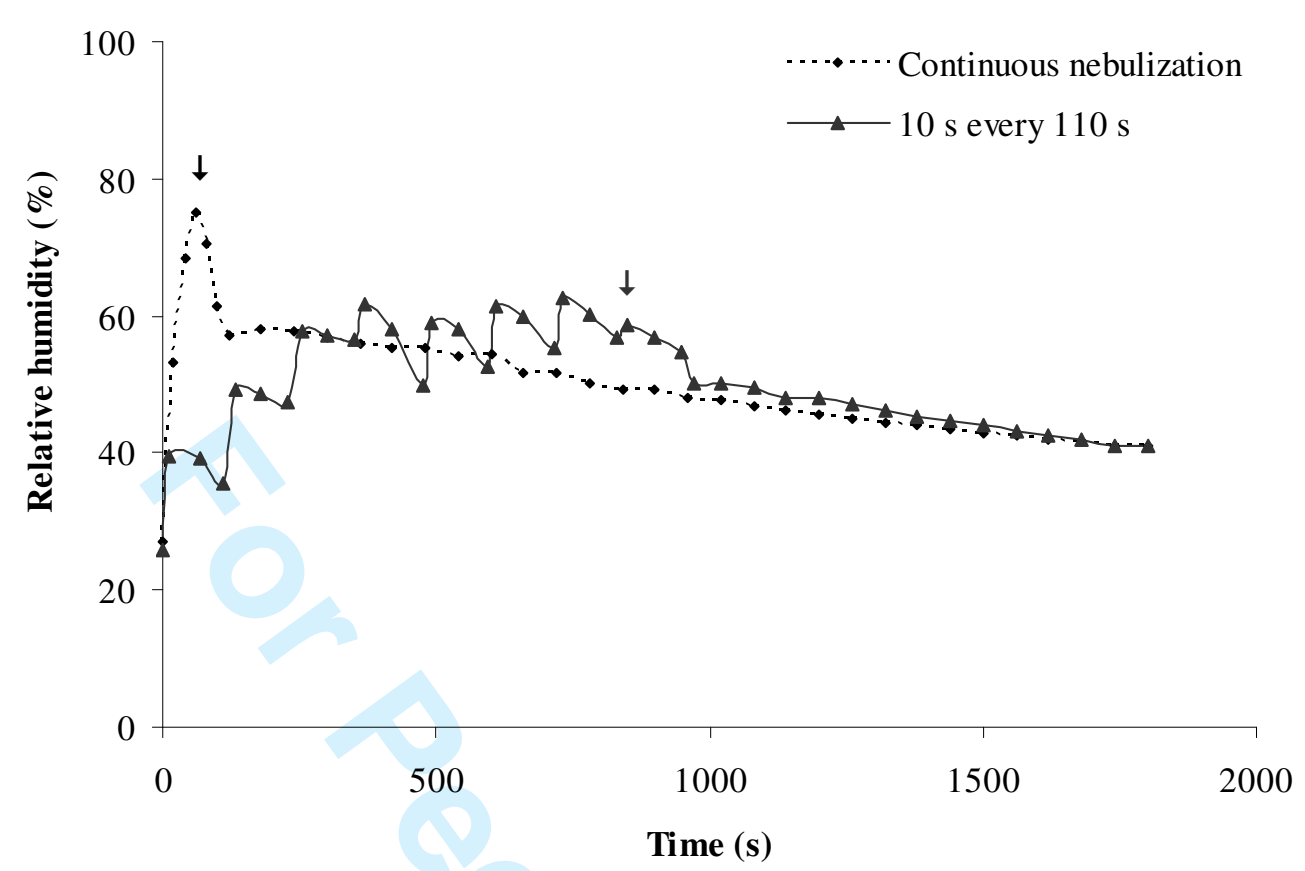

Figure 3. Relative humidity $(R H)$ in the exposure chamber upon nebulization of $1.5 \mathrm{ml}$ of water with the Walther Pilot I spray-head (spray rate $=1.25 \mathrm{ml} / \mathrm{min}$ and nebulizing air pressure $=0.5$ bar). $R H$ was measured at different points of time after the start of the nebulization and evaluated for different spraying procedures $(n=1)$. The arrows indicate the end of the nebulization period: 70 s for the continuous nebulization and 14 min for the interval nebulization. 


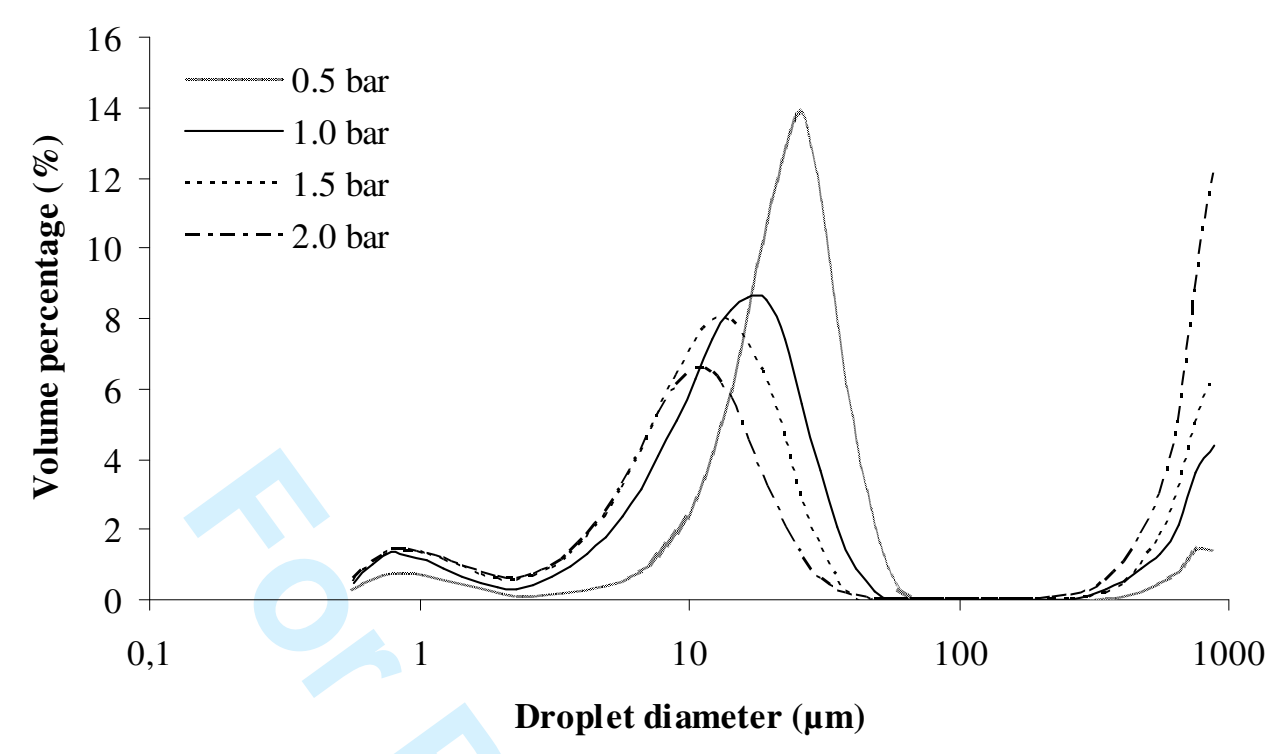

Figure 4. Average droplet size distribution $(n=3)$ produced by the Walther Pilot I sprayhead for increasing nebulizing air pressures (spray rate $=1.25 \mathrm{ml} / \mathrm{min}$ ). The results are expressed as a volume distribution (i.e. percentage of droplets with a certain volume are plotted in function of their diameter). 


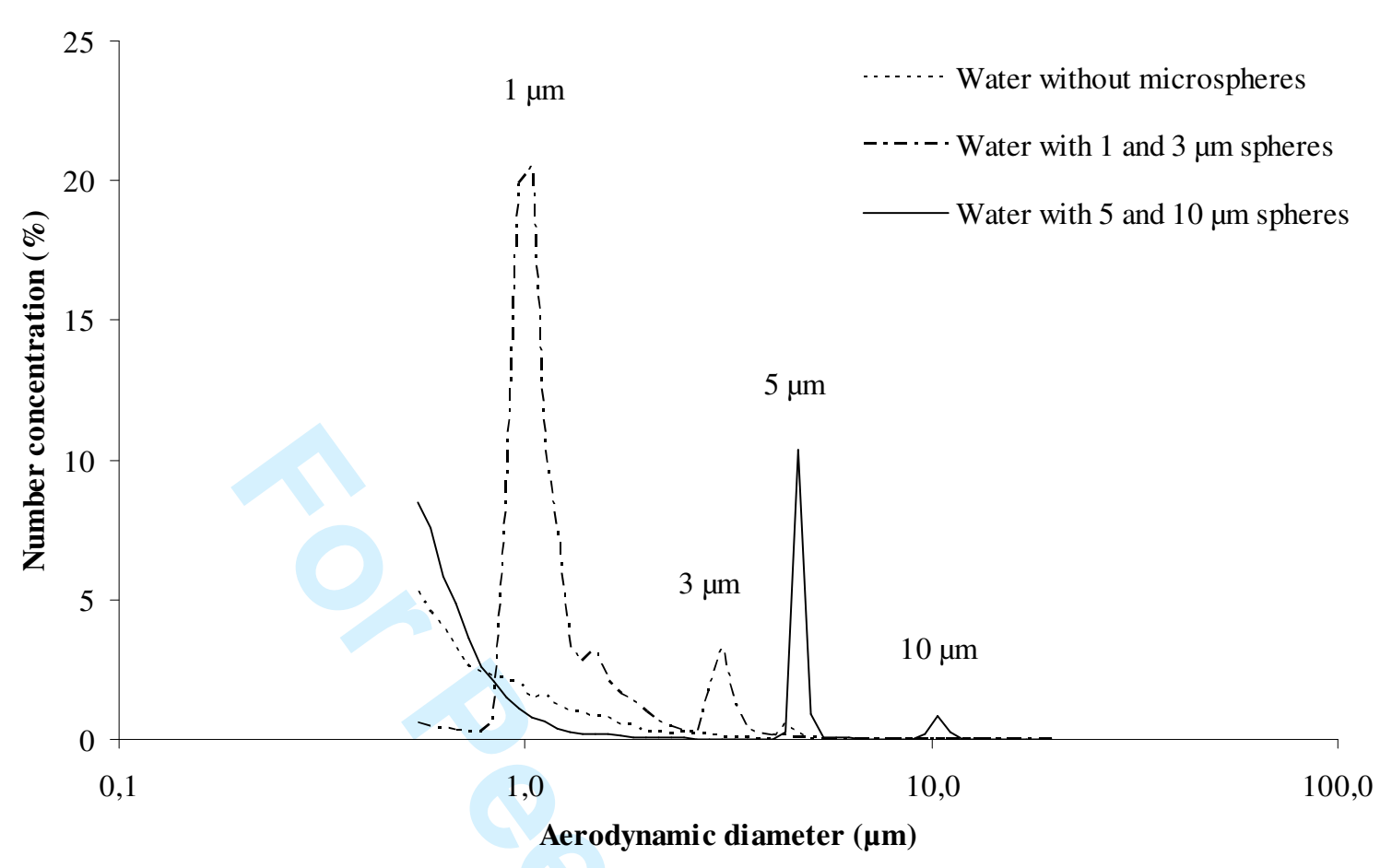

Figure 5. Average aerodynamic particle diameters detected on the bottom of the exposure chamber $(n=2)$ after nebulization of water without microspheres and nebulization of microsphere suspensions. Sharp, symmetrical peaks indicate complete evaporation of the water film around the microspheres. 
A

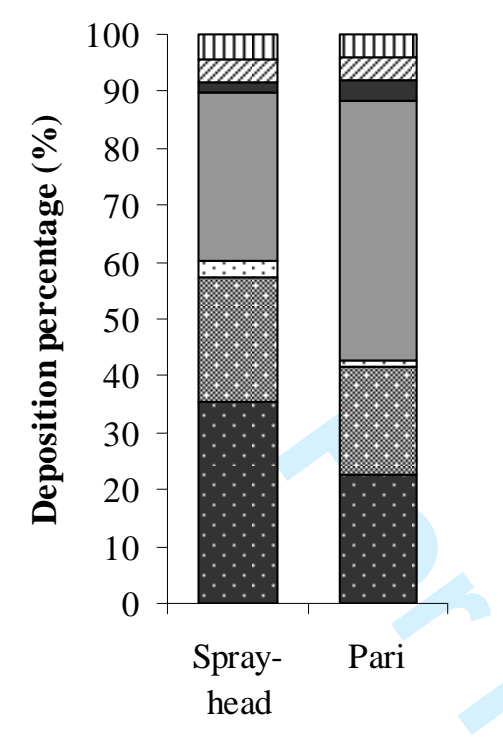

B

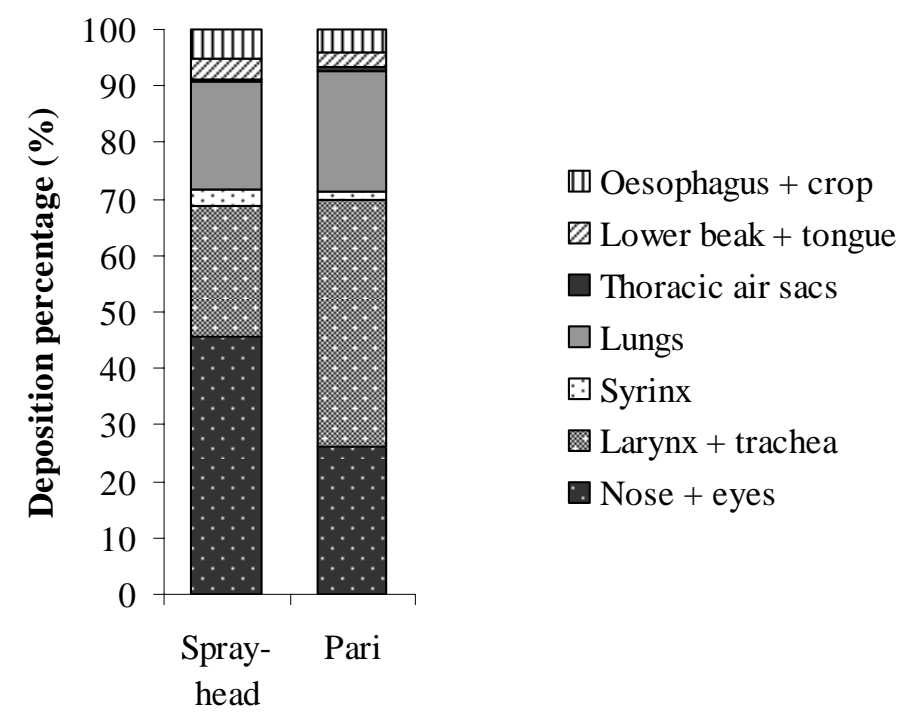

Figure 6. Evaluation of deposition of microspheres (A: $1 \mu \mathrm{m}$ spheres; B: $3 \mu \mathrm{m}$ spheres) in 2week-old broiler chickens using the Walther Pilot I spray-head $(n=10)$ and the Pari nebulizers $(n=5)$. The dotted segments represent the deposition in the upper airways (i.e. nose and eyes, larynx with trachea and syrinx), the plain segments comprise the deposition in the lower airways (i.e. lungs and thoracic air sacs), and the striped segments show the amount of microspheres in part of the gastro-intestinal tract (i.e. lower beak with tongue and oesophagus with crop). Although some differences can be observed, these are not significant, except for the 1 um spheres deposited in the lungs and the thoracic air sacs. 
A

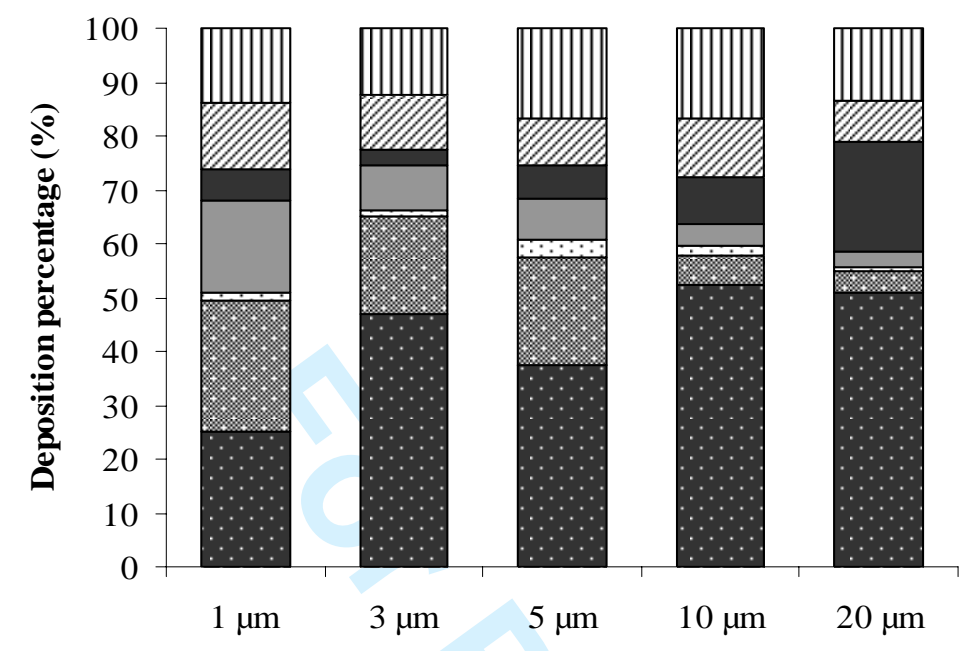

B

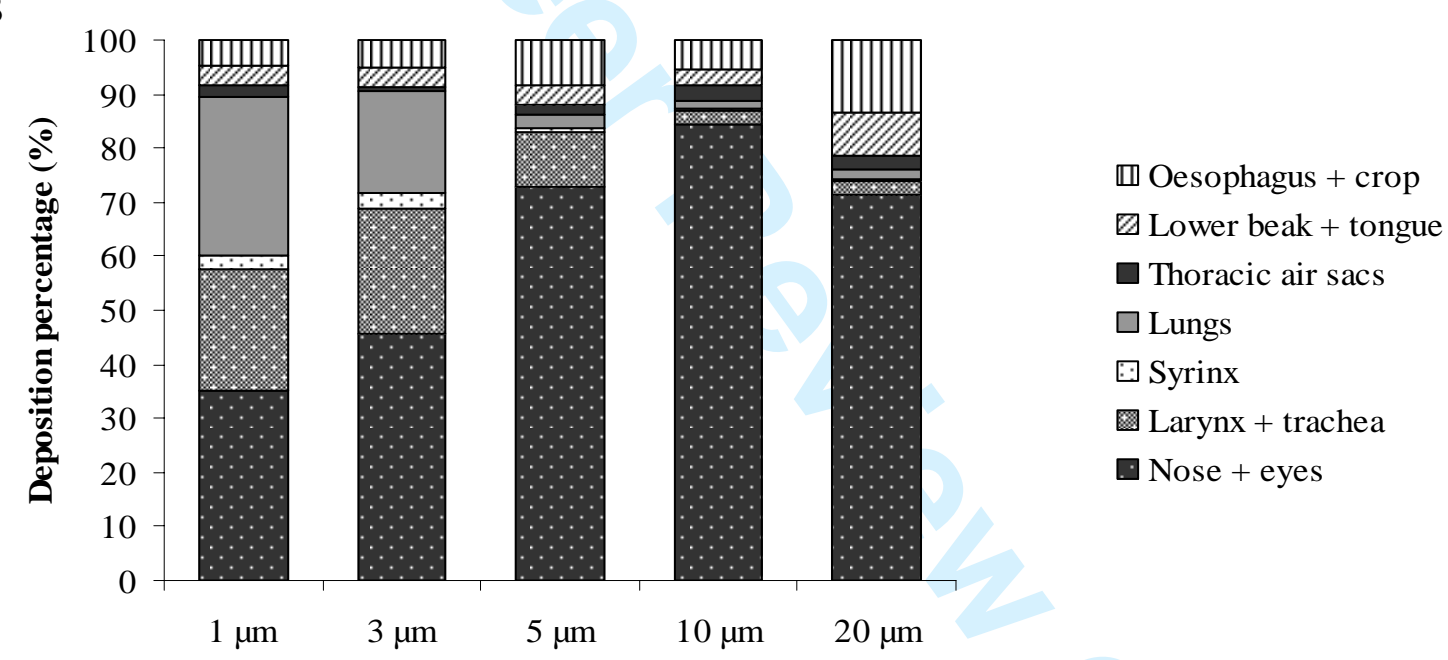

C

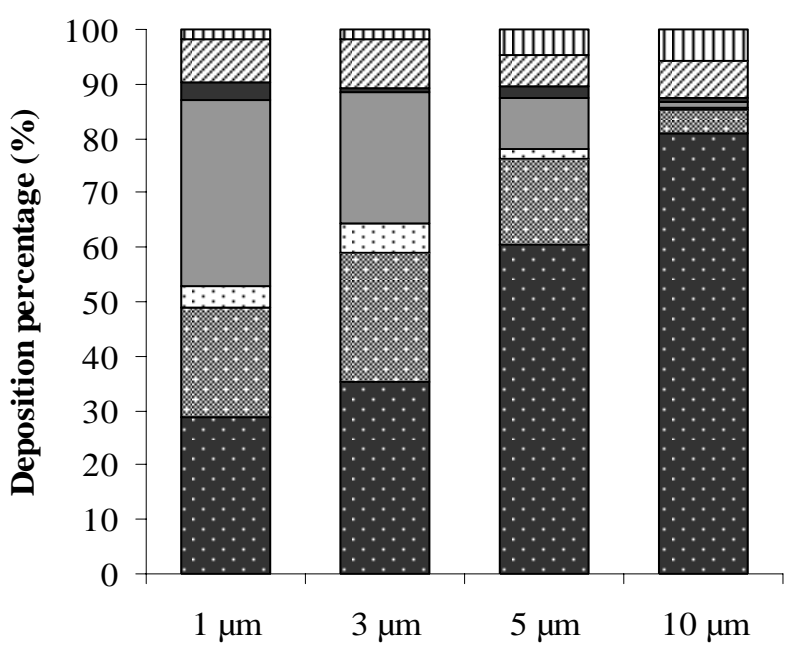


Figure 7. Average deposition percentages in broilers of different ages (A: day-old; B: 2weeks-old; C: 4-weeks-old) after nebulization of differently sized fluorescent microspheres with a Walther Pilot I spray-head. For each aerosol type (1 and $3 \mu \mathrm{m} ; 5$ and $10 \mu \mathrm{m} ; 20 \mu \mathrm{m}$ ) 10 birds were used. The dotted segments represent the deposition in the upper airways (i.e. nose and eyes, larynx with trachea, syrinx), the plain segments comprise the deposition in the lower airways (i.e. lungs and thoracic air sacs), and the striped segments show the amount of microspheres in the anterior part of the gastro-intestinal tract (i.e. lower beak with tongue, oesophagus with crop). 